\title{
Delegation in international monetary policy games*
}

Juan J. Dolado

Bank of Spain, Madrid, Spain and CEPR, London, UK

\section{Mark Griffiths}

Virginia Polytechnical Institute \& State University, Blacksburg, VA, USA

\section{A. Jorge Padilla}

CEMFI, Madrid, Spain and CEPR, London, UK

Received January 1992, final version received October 1992

In this paper, we show that delegation of monetary policy to an independent and more conservative central banker is an optimal policy in a multi-country framework with monetary
spillovers among countries, even in the absence of time inconsistency (credibility) issues. We also study the welfare implications of delegating monetary policy and extend our analysis to the case of coordination of monetary policies.

\section{Introduction}

Some recent studies have shown that an individual may be able to commit to a given action if her choice is delegated to another individual with the to an with the suitable preferes. international and Gray (1985). We analyse the incentives of national governments to delegate the control of monetary policy to independent central bankers with their own output-inflation preferences. Delegation is used by governments as a device to commit to a given monetary policy in the context of a heavily interrelated world economy. *We are grateful to J. Ayuso, D. Cohen, J.M. González, D. Laskar, J. Mélitz, R. Repullo, J. Viñals, C. Wyplosz, two anonymous referees and participants in seminars in Madrid and Paris

for their helpful comments. The usual caveat applies.
'For example, Vickers (1984), Fershtman and Judd (1987) and Gatsios and Karp (1991). 
We focus on a two-stage monetary game where governments first choose the type of central bankers in charge of their respective monetary policies, and secondly, central bankers set the money growth rates for their ow countries. ${ }^{2}$ We concentrate on a two-country world economy where countries have structurally identical economies but are endowed with differen output-inflation preferences. The two economies are interrelated through monetary spillovers (positive or negative) which link output growth at home with foreign monetary policy. In this framework, Canzoneri and Gray (1985) showed that countries under-expand (over-expand) their money supplies in reaction to a negative common supply

Delegation of monetary policy on independent central bankers characterises the equilibrium of this monetary game. Note that the novel result in this paper is that delegation arises because of the existence of monetary spillover across countries in an international context, and in the absence of any time inconsistency issues stemming from the lack of credibility of the monetary authorities. ${ }^{3.4}$

Each government delegates its monetary policy to an independent and more conservative (that is, with a greater dislike for inflation) central banker in order to commit to a tighter monetary policy. When monetary spillovers are positive this forces the other country to act as a locomotive bearing the inflationary costs of the world adjustment to the common shock. Furthermore, since both countries choose conservative bankers, delegation imposes an additional deflationary bias onto the world economy and this makes both an additional deflationary bias onto the world economy and this makes both
countries worse off. On the contrary, in a world with negative monetary spillovers, delegation helps reducing the excessive rates of money growth without a large cost in terms of output. Delegation of monetary policy in this latter case is thus welfare improving.

The incentives of national governments to mis-represent their true output-

${ }^{2}$ We consider this to be the natural sequence of policy choices. The decision to set up an independent central banker in charge of monetary policy is a long-run decision which in many cases is a constitutional matter, and in most other cases cannot be easily reversed. This contras ${ }^{3}{ }^{3}$ Following the analysis in Barro and Gordon (1983), Rogoff (1985 a b) showed how.

to an independent and conservative central banker may solve the time inconsistency proble which characterises monetary policy intertemporally. See also Buiter and Marston (1985). Glavazzi and Pagano (1988), Currie et al. (1989) for the possibility of 'importing' credibility in an open economy. A complementary approach to our paper can be found in Laskar (1990) and However, in their papers delegation arises mainly because of the existence of time-inconsistency problems. Furthermore, delegation is always welfare reducing which is shown in our paper not to be necessarily true.

IIf credibility issues were incorporated to our model, our results on delegation would be strengthened when supply shocks are symmetri. If shocks were asynn inflation preferences are also present when monetary policies are coordinated by a supra-national authority but where there is no cooperation in the choice of central bankers. Again, governments pretend to dislike inflation to a larger extent than they truly do independently of the sign of the monetary spillovers.

The rest of the paper is organised as follows. Section 2 presents the model In section 3 , we analyse the choice of central banker when monetary policy is monetary policies. Section 5 concludes.

\section{The model}

Two countries with closely interrelated economies, A and B, play a two-stage monetary policy game. In the first stage, or delegation stage, the government of each country chooses (independently and simultaneously) the type of central banker to whom delegate monetary policy. In the second type of central banker to whom delegate monetary policy. In the second
stage, the central bankers previously elected set simultaneously money stage, the central bankers previously
growth rates for their respective countries.

growth rates for their respective countries. The (output-inflation) preferences of
the following quadratic utility function:

$$
\bar{V}_{i}=-1 / 2\left(y_{i}^{2}+\mu_{i} \pi_{i}^{2}\right), \quad i=\mathrm{A}, \mathbf{B} .
$$

Governments value negatively deviations around an optimal value of zero inflation, and also deviations of total output from a given equilibrium value. (Both such deviations are denoted by $\pi_{i}$ and $y_{i}$, respectively.) Note that $\mu_{i} \geqq 0$ represents the true government $i$ 's relative preferences between output and inflation. A larger value of $\mu_{i}$ shows a proportionately greater dislike for inflation.

Let $v_{i} \geqq 0$ index the different types of central bankers who are available to government $i(i=\mathrm{A}, \mathrm{B})$ at the delegation stage. Government $i$ chooses $v_{i}$ (we shall denote by $v_{i}^{*}$ the actually chosen value of $v_{i}$ ) to maximise its utility $\bar{V}_{i}$ knowing that the country's money growth rates will be chosen to maximise the output-inflation preferences of the elected central banker.

$$
V_{i}=-1 / 2\left(y_{i}^{2}+v_{i}^{*} \pi_{i}^{2}\right) .
$$

No delegation occurs when $v_{i}^{*}=\mu_{i}{ }^{5}$ Otherwise, an independent central banker with different output-inflation preferences is let to rule monetary policy.

${ }^{5}$ Note that even though (2) is the relevant objective function for the second stage subgame, the equilibrium outcomes of the overall game have to be judged according to eq. (1) 
Finally, the two-country economy is summarised by the following spillover equations: ${ }^{6}$

$$
y_{i}=a_{1} m_{i}+a_{2} m_{j}-z,
$$

$$
\pi_{i}=m_{i}
$$

where $i, j=\mathrm{A}, \mathrm{B}$ and $i \neq j ; 1>a_{1}>\left|a_{2}\right| \geqq 0$; and, $z \geqq 0$.

Deviations of output depend on the domestic and foreign money growth rates and an unfavourable supply shock, $z \geqq 0$. Inflation is assumed to depend only on the country's own money growth rate. ${ }^{7}$ Note that $a_{1}$ is assumed to be positive, that is, a faster expansion of the domestic money supply increases domestic output. No sign can be imposed a priori on $a_{2}$ because the transmission of monetary shocks across countries may have ambiguous effects, ${ }^{8}$ yet it is assumed that the domestic monetary multiplier, $a_{1}$, is larger than the foreign monetary multiplier $\left|a_{2}\right|$.

In what follows, we shall study the Subgame Perfect Nash Equilibria of this two-stage monetary game.

\section{Delegating monetary policy to independent central banks}

We begin analysing the choice of central bankers when monetary spillovers are positive, $a_{2}>0$. Then, we extend our analysis to the case of negative spillovers, $a_{2}<0$

\subsection{Equilibrium money growth rates}

Given the output-inflation preferences of the central bankers elected at the delegation stage, $v_{\mathrm{A}}^{*}$ and $v_{\mathbf{B}}^{*}$, the equilibrium money growth rates of countries $\mathrm{A}$ and $\mathrm{B}, m_{\mathrm{A}}$ and $m_{\mathrm{B}}$ satisf

Lemma $1 .{ }^{9} \quad$ For any pair $\left(v_{\mathrm{A}}^{*}, v_{\mathrm{B}}^{*}\right)$, there exists a unique Nash equilibrium, for the second stage subgame. In this equilibrium money growth rates are given by

${ }^{6}$ This two-country model is a simplified version of Canzoneri and Gray (1985). We assume for simplicity that both countries are structurally identical and may differ only in their outputinflation preferences. Nevertheless, our basic intuitions will also apply to an asymmetric versio of this model. Furthermore, our basic result will also extend naturally to an $n$-country version of

resuls. Nothing assumption makes the algebra less cumbersome and sharpens the theoretical There is little even if $m_{j}$ does not affect $\Pi_{i}$, it does affect $V_{i}$ through its impact on $y_{i}(i \neq j)$. (1988) presents a survey of the various transmission mechanisms and compares them with the ntry macro-econometric model

working paper version of this
$m_{B}$

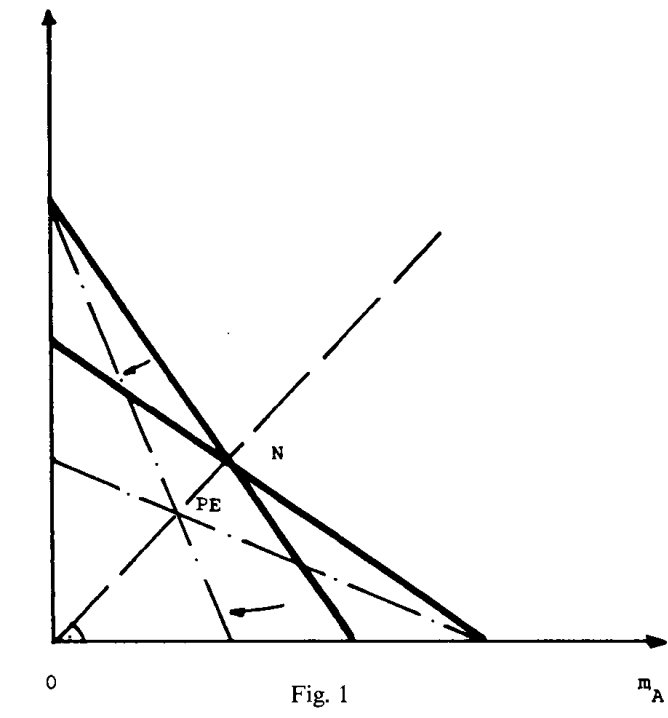

$m_{i}^{*}=\left(v_{j}^{*}+a_{1}^{2}-a_{1} a_{2}\right) a_{1} z / \Delta, \quad i, j=\mathrm{A}, \mathrm{B}, \quad i \neq j$,

where $\Delta=\left(v_{\mathrm{A}}^{*}+a_{1}^{2}\right)\left(v_{\mathrm{B}}^{*}+a_{1}^{2}\right)-a_{1}^{2} a_{2}^{2}$.

When monetary spillovers are positive, the money growth rates of the two countries are strategic substitutes (see fig. 1): ${ }^{10}$ If country B increases its rate counties are strategic substitues (see fig 1): ${ }^{10}$ If country B increases its rate of monetary expansion A's output grows faster. Hence, there is less iseed for an increase in A's money grow $\mathrm{rate}, m_{\mathrm{A}}$, and some additional scope to A's inflation via a reduction of its money growth rate $m_{\mathrm{A}}$

An increase in B's money growth rate thus creates a positive externality on country A and vice versa. The Nash equilibrium described in Lemma 1 is characterised by sub-optimally low money growth rates precisely because countries fail to internalise this positive externality. (Note that $\partial V_{j} / \partial m_{i}>0$ at $m_{i}=m_{i}^{*}$ )

\subsection{The delegation game}

Government $i(i=\mathrm{A}, \mathrm{B})$ chooses the output-inflation preferences of its central banker, $v_{i}^{*}$, to maximize its objective function $\bar{V}_{i}$ as given in eq. (1) Note that under the current assumption that monetary spillovers are

${ }^{10}$ In the terminology of Bulow et al (1985). 
positive, if country $i$ chooses $v_{i}^{*}>\mu_{i}$, that is, if it delegates on a conservative central banker, i.e., a banker with tougher preferences against inflation, then it commits country $i$ to a lower rate of monetary growth for any rate of money growth of country $j$. Furthermore, country $j$ is induced to raise it own rate of money growth, $m_{j}$, to offset the deflationary impact on its output of country $i$ 's monetary contraction.

From Lemma 1, if $v_{i}^{*}>\mu_{i}$, then country $i$ 's equilibrium money growth rate falls $\left(\partial m_{i}^{*} / \partial v_{i}<0\right)$ while country $j$ 's equilibrium money growth rate increase $\left(\partial m_{j}^{*} / \partial v_{i}>0\right)$. (Fig. 1 presents this argument diagrammatically for the where country A chooses $v^{*}>\mu_{A}$. Note that with positive spillovers, country $A$ 's welfare is increased at the new equilibrium.)

Proposition 1. There is a unique perfect equilibrium for the delegation game. In this equilibrium, the governments of both countries delegate their monetar policies to independent and more conservative central bankers i.e., $v_{i}^{*}=$ $\mu_{i}\left(v_{j}^{*}+a_{1}^{2}\right) /\left(v_{j}^{*}+a_{1}^{2}-a_{2}^{2}\right) \geqq \mu_{i} \geqq 0 i, j=\mathrm{A}, \mathrm{B} ; i \neq j$.

\section{Proof. See appendix.}

Delegation of monetary policy to an independent and conservative central banker is indeed a dominant strategy for countries with interrelated economies. It is easy to show that, for any value of $v_{j}^{*}, \partial \bar{v}_{i} / \partial v_{i}$ is positive at $v_{i}=\mu_{i}$ as long as $a_{2} \neq 0$. Furthermore, the more integrated are the economies of the two countries (the larger $a_{2}$ ), the greater is the incentive to delegate on a two countries (the larger $a_{2}$ ), the greater is the incentive to delegate on a
conservative banker, $\partial v_{i}^{*} / \partial a_{2}>0$. Only if the two economies were completely conservative banker, $\partial v_{i}^{*} / \partial a_{2}>0$. Only if the two economies were completely
isolated from each other $\left(a_{2}=0\right)$, the strategic incentives to delegate on a isolated from each other $\left(a_{2}=0\right)$, the strategic incentives to delegate on a conservative banker would vanish.

Delegation of monetary policies exacerbates the intrinsic deflationary bias of the world economy when monetary spillovers are positive. In Proposition 1 we saw that in equilibrium each country chooses a conservative central banker to run its monetary policy which implies lower equilibrium money growth rates than in the absence of delegation, $m^{*}\left(v^{*}, \nu^{*}\right) \leq m^{*}\left(\mu_{A}, \mu_{0}\right)$ Hence, delegation makes both countries worse off 12 Fig 1 above $m_{i}\left(\mu_{\mathrm{A}}, \mu_{\mathrm{B}}\right)$ the sub-optimality of the pefect equilibius the sub-optimlity of the pame (PE) with respect to the Nash equilibrium of the monetary policy game when policy cannot be delegated $(\mathrm{N})$.

Assume, for simplicity, that the output-inflation preferences of both countries are symmetric, i.e., $\mu_{\mathrm{A}}=\mu_{\mathrm{B}}=\mu$. Then, in equilibrium each countr delegates on a central banker with preferences given implicitly by ${ }^{11}$ Delegation to a conservative central banker is only optimal in a closed economy framework
if there are important time inconsistency problems affecting monetary policy (see Rogoff

${ }^{2}$ The delegation game behaves like a typical prisoners' dilemma when $a_{2}>0$.

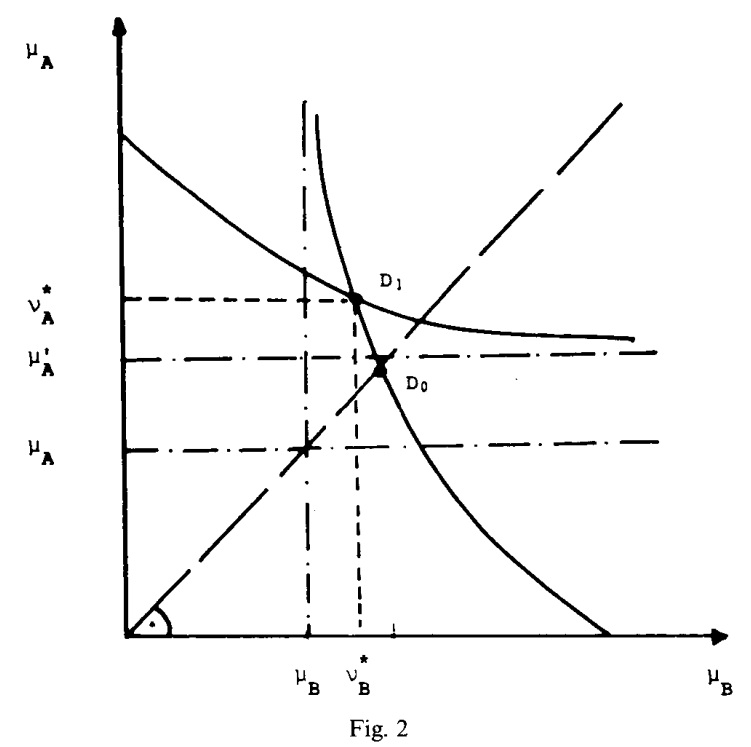

$v^{*}=\mu\left[\left(v^{*}+a_{1}^{2}\right) /\left(v^{*}+a_{1}^{2}-a_{2}^{2}\right)\right] \geqq \mu$.

From eq (5) $\partial v^{*} / \partial \mu>0$, that is, the more averse to inflation are the two countries, the more conservative are the central bankers in charge of monetary policy. Now if, for instance, country $\mathrm{A}$ were to become more inflation averse, $\mathrm{d} \mu_{\mathrm{A}}>0$, it would tend to choose a more conservative central banker than country B. Note that $\partial v_{\mathrm{A}}^{*} / \partial \mu_{\mathrm{A}} \geqq 0 \geqq \partial v_{\mathbf{B}}^{*} / \partial \mu_{\mathrm{A}}$ so that $v_{\mathrm{A}}^{*} \geqq v_{\mathrm{B}}^{*}$ Furthermore, country $\mathrm{A}$ would also distort its true output-inflation preferences proportionately more than country $\mathbf{B}$, that is, $\mu_{\mathbf{A}}>\mu_{\mathbf{B}}$ implies $v_{\mathrm{A}}^{*} / \mu_{\mathbf{A}}>$ $v_{\mathrm{B}}^{*} / \mu_{\mathrm{B}}$. In fig. 2 , an increase from $\mu_{\mathrm{A}}=\mu_{\mathrm{B}}$ to $\mu_{\mathrm{A}}^{\prime}>\mu_{\mathrm{B}}$ shifts the equilibrium of the delegation game from $D_{0}$ to $D_{1}$ illustrating these two comments.

3.3. The case of negative spillovers

The analysis of this latter case is basically identical to that in the previous subsections. In particular, Lemma 1 and Proposition 1 are still valid if $a_{2}$ is set to be negative. For $a_{2}<0$, money growth rates are strategic complements rather than strategic substitutes and, therefore, monetary reaction functions are upward sloping (see fig. 3). An increase in B's money growth rate decreases A's output and induces $A$ to increase its monetary growth rate to offset the fall in its output. 


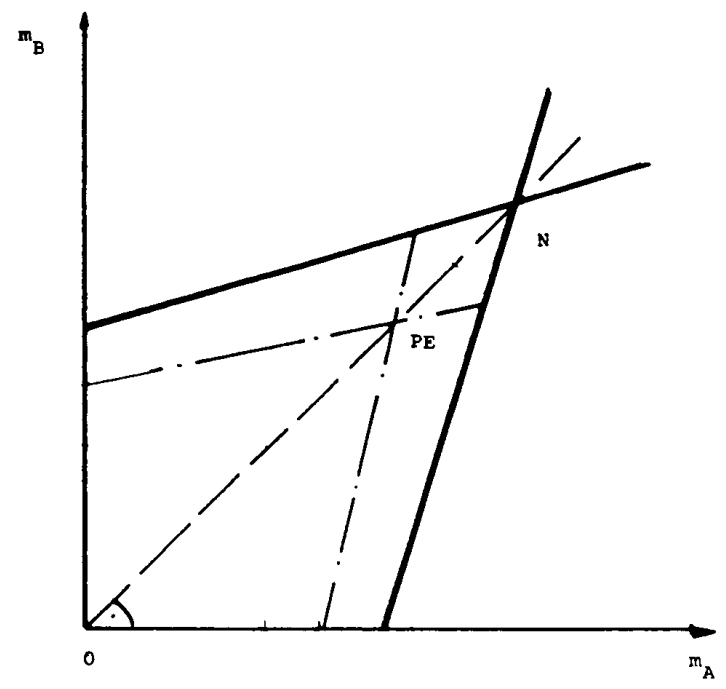

Fig. 3

From Lemma 1, the Nash equilibrium for the second stage subgame is characterised by excessive monetary growth because countries fail to internalise the negative monetary externality that they impose on each other. [Note that the two countries are better off if the equilibrium is located to the South-West of $(\mathrm{N})$ where money growth rates are low.]

As in the case of positive spillovers, each country has an incentive to delegate on conservative central bankers. In fact, $\partial \bar{V}_{i} / \partial v_{i}$ at $v_{i}=\mu_{i}$ is positive irrespective of the sign of $a_{2}$. By delegating its monetary policy to a highly inflation averse central banker a country commits to a tighter monetary policy which helps against inflation, damages output at home and increases output abroad.

In equilibrium both countries implement a tight monetary policy by means of delegation because the positive effects on inflation outweigh the deterioration of output. Furthermore, delegation makes both countries better off by reducing the excessive monetary growth which characterises the monetary game with negative spillovers. This again can be observed in fig. 3 , where the perfect equilibrium of the delegation game (PE) is located to the South-West of point $(\mathrm{N})$, that is, in the area of increased utility for both countries.

\section{Strategic manipulation of coordinated monetary policies}

Suppose that national monetary policies are coordinated by a Supra- national Monetary Authority (SMA) ${ }^{13}$ but that central bankers are still chosen non-cooperatively. The SMA sets $m_{\mathrm{A}}, m_{\mathrm{B}}$, the money growth rates of the two countries, to maximise joint welfare $W\left(m_{\mathrm{A}}, m_{\mathrm{B}}\right)=V_{\mathrm{A}}+V_{\mathrm{B}}$, where $V_{\mathrm{A}}$ and $V_{B}$ are given in eq. (2) above. Note that the SMA's decisions on money growth take as given the output-inflation preferences declared by the member countries (A and $\mathbf{B}$ ), $v_{\mathrm{A}}$ and $v_{\mathrm{B}}$, in the first stage of the monetary game. Those preferences will not generally coincide with the true preferences $\mu_{\mathrm{A}}, \mu_{\mathrm{B}}$. Solving the SMA's problem, we obtain the following result:

Lemma $2 .{ }^{14}$ For any pair $\left(v_{\mathrm{A}}, v_{\mathrm{B}}\right)$, the money growth rates set by the $\mathrm{SMA}$ are given by

$$
\tilde{m}_{i}=\left(a_{1}+a_{2}\right)\left[v_{j}+\left(a_{1}-a_{2}\right)^{2}\right] z / \Delta^{\prime}, \quad i, j=\mathrm{A}, \mathbf{B}, \quad i \neq j,
$$

where $\Delta^{\prime}=\left(v_{\mathbf{A}}+a_{1}^{2}+a_{2}^{2}\right)\left(v_{\mathbf{B}}+a_{1}^{2}+a_{2}^{2}\right)-4 a_{1}^{2} a_{2}^{2}$.

We can compare the money growth rates that prevail when monetary policies are coordinated $\left(\tilde{m}^{\prime} s\right)$ with the rates that would have prevailed had country retained control of its monetary policy $\left(m^{* \prime} s\right)$. For simplicity, assume that $v_{\mathrm{A}}=v_{\mathrm{B}}=v \geqq 0$ (i.e., declared preferences are symmetric). Then, it is easy to see from Lemmas 1 and 2 that $\operatorname{sign}\left[\tilde{m}=m^{*}\right]=\operatorname{sign}\left[v a_{2}\right]$. Therefore, when $a_{2}$ is positive, the SMA reduces the deflationary bias of independent monetary policies, internalising the (positive) monetary externalities between its member countries. However, when $a_{2}$ is negative the SMA eliminates the

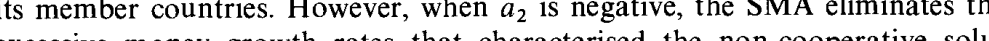
excessive money grow th rates that charactu tion. Coordination of monetary policy leads to Pareto efrciency. (For the sake of brevity, we shall concentrate on the case of positive spillovers in the rest of this section.)

Note that at $m_{i}=\tilde{m}_{i}, \partial \bar{V}_{i} / \partial m_{i}$ is negative for all $i$ which means that each country would prefer a lower money growth rate than that imposed by the SMA. Country $i$ thus has an incentive to declare a greater dislike for inflation than the truly held in order to induce the SMA to set a lower $\tilde{m}_{i}$ (and also a higher money growth rate for country $j, \tilde{m}_{j}$ ), an action which unambiguously benefits country $i$. Note that $\partial \tilde{m}_{i} / \partial v_{i}<0$ and $\partial \tilde{m}_{j} / \partial v_{i}>0$ where $i, j=\mathrm{A}, \mathrm{B}$ and $i \neq j$

As in the previous section, countries choose their declared preferences, now As in the previous section, countries choose their dectared preferences, now ximise their $\sigma_{\text {, }}$ in

${ }^{13} \mathrm{An}$ instance of an SMA are the G7 meetings where the most industrialised countries 'coordinate' their molary policies. Studies on monetary policy coordination include Oud

${ }^{14}$ The proof of this lemma is trivial and hence omitted. 
Proposition 2. In equilibrium, each country declares output-inflation preferences, $\tilde{v}_{i}$, which involve a greater dislike for inflation than the truly held. That is, $\tilde{v}_{i} \geqq \mu_{i} \geqq 0$ for all $i$.

Proof. See appendix

For the symmetric case where $\mu_{\mathrm{A}}=\mu_{\mathrm{B}}=\mu$, both countries declare outputinflation preferences equal to

$$
\tilde{v}=\mu\left(a_{1}+a_{2}\right)\left(\tilde{v}+a_{1}^{2}+a_{2}^{2}\right) /\left(a_{1}\left(\tilde{v}+a_{1}^{2}-a_{2}^{2}\right)\right] .
$$

Comparing (6) and (5) above, we conclude that the incentives to distort the true output-inflation preferences are increased when monetary policy is not carried out at the national level but by an SMA. Since the SMA tends to overexpand monetary policy with respect to the non-cooperative solution when monetary spillovers are positive, the need for commitment to a tighter monetary stance is greater. Thus, governments distort their true preferences to a larger extent.

Only if the SMA were restricted to set $m_{\mathrm{A}}=m_{\mathrm{B}}=m$, governments' incentives to manipulate the SMA via distortion of their true output-inflation preferences would disappear. In this case, a simultaneous contraction of domestic monetary growth rates and a monetary expansion abroad is no longer feasible. ${ }^{15}$

The distortion of the output-inflation preferences of governments clearly affects the optimality properties of a coordinated monetary policy. The SMA can no longer achieve Pareto efficient outcomes. When $\mu_{\mathrm{A}}=\mu_{\mathrm{B}}=\mu$, making use of (5) and (6), we can establish unambiguous welfare comparisons between different forms or organising monetary policy. For instance when $a_{2}>0$, the welfare ordering is: monetary policy organised by an SMA, an SMA with manipulation of preferences, independent national monetary policies, and finally, independent monetary policies with delegation to conservative central bankers.

\section{Conclusions}

In this paper we have shown that the incentive to delegate monetary policy on independent central bankers is not solely connected with time

${ }^{15}$ Existence of equilibrium for the overall game with $m_{\mathrm{A}}=m_{\mathrm{B}}=m$ requires that there is enough $\mu_{\mathrm{A}}=\mu_{\mathrm{B}}$. When $m_{\mathrm{A}}=m_{\mathrm{B}}$, each country would like the SMA to behave under its own output inflation preferences. The interests of both countries with respect to the SMA are only compatible if their underlying output-inflation preferences do coincide. This is precisely the wellworking paper version for a forg hit pe ox of the rales requirs a com This is pecisy inconsistency (credibility) problems. We show that the existence of monetary spillovers in a multi-country framework also leads to the delegation of monetary policies.

Governments choose more conservative central bankers as a way to commit to a more restrictive monetary policy independently of the sign of the monetary spillovers. However, the sign of these spillovers determines the welfare implications of delegation. If these spillovers are positive, delegation is welfare reducing but if, on the contrary, they are negative delegation makes every country better off.

We finally show that the incentives to distort the true output-inflation preferences of each government are still present even if monetary policies are coordinated by a supra-national authority.

\section{Appendix}

Proof of Proposition 1

Given that

$$
\bar{V}_{i}=-1 / 2\left(y_{i}^{2}+\mu_{i} m_{i}^{2}\right), \quad i=\mathrm{A}, \mathrm{B},
$$

the first-order condition w.r.t. $v_{i}$ is

$$
\begin{aligned}
\partial \bar{V}_{i} / \partial v_{i} & =\left(\partial \bar{V}_{i} / \partial m_{i}\right)\left(\partial m_{i} / \partial v_{i}\right)+\left(\partial \bar{V}_{i} / \partial m_{j}\right)\left(\partial m_{j} / \partial v_{i}\right) \\
& \left.=-\left[y_{i} a_{1}+\mu_{i} m_{i}\right)\left(\partial m_{i} / \partial v_{i}\right)-y_{i} a_{2}\left(\partial m_{j} / \partial v_{i}\right)\right]=0 .
\end{aligned}
$$

From Lemma 1 we have

Hence

$$
\partial m_{j} / \partial v_{i}=-\left(\partial m_{i} / \partial v_{i}\right)\left[a_{1} a_{2} /\left(v_{j}+a_{1}^{2}\right)\right] .
$$$$
\partial \bar{V}_{i} / \partial v_{i}=-\left(\partial m_{i} / \partial v_{i}\right)\left[\mu_{i} m_{i}-v_{i}^{*} m_{i}+v_{i}^{*} m_{i} a_{2}^{2} /\left(v_{j}^{*}+a_{1}^{2}\right)\right]=0,
$$

that is

$$
v_{i}^{*}=\mu_{i}\left[\left(v_{j}^{*}+a_{1}^{2}\right) /\left(v_{j}^{*}+a_{1}^{2}-a_{2}^{2}\right)\right]
$$

with $i, j=\mathrm{A}, \mathrm{B}$ and $i \neq j$

The second-order condition for a maximum, after substituting the firstorder condition is

with

$$
\partial^{2} \bar{V}_{i} / \partial v_{i}^{2}=-\left(\partial m_{i} / \partial v_{i}\right) \lambda_{j} m_{i}<0,
$$

Since

$$
\lambda_{j}=\left[a_{2}^{2} /\left(v_{j}^{*}+a_{1}^{2}\right)\right]-1, \quad i, j=\mathrm{A}, \mathrm{B}
$$

$\operatorname{sign}\left(\partial m_{i} / \partial v_{i}\right)<0$ 
$\operatorname{sign}\left(\partial^{2} \bar{V}_{i} / \partial v_{1}^{2}\right)=\operatorname{sign}\left(a_{1}^{2}-a_{1}^{2}-v_{j}\right)<0$

given that $a_{1}>\left|a_{2}\right|>0$ and $v_{j}^{*}>0$.

Proof of Proposition 2

From Lemma 2

where

$$
\partial m_{j} / \partial v_{i}=-\gamma_{j}\left(\partial m_{i} / \partial v_{i}\right)
$$

Hence

$$
\gamma_{j}=2 a_{1} a_{2} /\left(v_{j}+a_{1}^{2} a_{2}^{2}\right)
$$

$$
\partial \bar{V}_{i} / \partial v_{i}=-\left[y_{i} a_{1}+\mu_{i} m_{i}-y_{i} a_{2} \gamma_{j}\right]\left(\partial m_{i} / \partial v_{i}\right)=0
$$

implies that

$$
\begin{aligned}
\tilde{v}_{i}= & \frac{\mu_{i}\left[\left(\tilde{v}_{j}+a_{1}^{2}+a_{2}^{2}\right)\left(\tilde{v}_{j}+\left(a_{1}-a_{2}\right)^{2}\right)\left(a_{1}+a_{2}\right)\right]}{\left[a_{1}\left(\tilde{v}_{j}+a_{1}^{2}-a_{2}^{2}\right)\left(\tilde{v}_{j}+a_{1}\right)\left(a_{1}-a_{2}\right)\right]} \\
& +\frac{a_{2}\left(a_{1}-a_{2}\right) \tilde{v}_{j}}{\left[\tilde{v}_{j}+a_{1}\left(a_{1}-a_{2}\right)\right]} \geqq \mu_{i} \geqq 0 .
\end{aligned}
$$

Following the same argument as in Proposition 1, it is easy to show that the second-order condition for a maximum also holds.

\section{References}

Alesina, A. and V. Grilli, 1992, The European Central Bank: Reshaping monetary policy in Europe, in: M. Canzoneri, V. Grilli and P. Masson, eds., Establishing a European Central
Bank: Issues in Europe and lessons from the US (Cambridge University Press, Cambridge). Bank: Issues in Europe and lessons from the US (Cambridge University Press, Cambridge).
Barro, R.J. and D.B. Gordon, 1983, A positive theory of monetary policy in a natural rate uiter, W.H. and R. . Marston, 1985, International economic policy coordination (Cambridec University Press, Cambridge).
Bulow, J., J. Geanakoplos and P. Klemperer, 1985, Multimarket oligopoly: Strategic substitutes and complements, Journal or Political Economy $93,488-5 k$. D. Currie, D., G. Holtham and A. Hughes-Hallett, 1989, The theory and practice of internationa policy coordination: Does coordination pay?, Discussion paper 325 (CEPR, London).

Delo, J.J., M. Griffiths and A.J. Padilla, 1992, Delegation in international monetary policy (a)

Dentives in oligopoly, American Economic Frankel, J.A., 1988, Obstacles to international macroeconomic policy coordination, Working paper no. 87/28 (International Monetary Fund, Washington, DC).

S Studies 58, 391-397.
Giavazzi, F. and M. Pagano, 1988, The advantage of tying one's hands: EMS discipline and central bank credibility, European Economic Review 32, 1055-1075.

Laskar, D., 1990, The tole of a fixed exchange rate system when cental bankers are

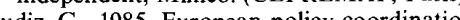

An evaluation, Discussion paper no. 81 (CEPR, Oudiz, G, and J Sachs, 1984, Macroeconomic policy coordination among the industrial economies, Brookings Papers on Economic Activity 1, 1-75.

Rogoff, K., 1985a, The optimal degree of commitment to an intermediate monetary target,

(6) counter-productive? Jounal of International Economics 18, 199-217. Vickers, J.S., 1984, Delegation and the theory of the firm, Economic Journal (Conference Proceedings) $95,138-147$. 